\title{
Organização tópica e sumarização do texto: estratégia para ensino de leitura
}

\author{
Clemilton Lopes Pinheiro (PINHEIRO, Clemilton Lopes) \\ Prof. Dr. Universidade Federal do Rio Grande do Norte - UFRN \\ clemiltonpinheiro@hotmail.com
}

\section{Resumo}

O objetivo deste trabalho é apresentar a topicalidade, um princípio organizador do texto, como um pressuposto para a realização de atividades de leitura. Propõe-se que o exercício de análise da organização tópica possibilita o desenvolvimento da habilidade de sumarização das informações, já que envolve, necessariamente, o processo de abstração dessas informações em macroproposições semânticas. A atividade de sumarização/resumo do texto pelo viés da sua organização tópica se reverte, portanto, em uma estratégia de ensino de leitura, concebida como processo estratégico e interativo de construção de sentido.

Palavras-chave: ensino, leitura, tópico discursivo, sumarização.

\begin{abstract}
This article proposes focusing on the topical organization of a text as a basis for teaching reading. In analyzing the organization of topics, students develop their ability to summarize information, for it involves processing information into semantic macropropositions. The activity of summarizing a text by examining the organization of its topics is a reading teaching strategy that can be conceived of as a strategic and interactive process in the construction of meaning.
\end{abstract}

Keywords: teaching, reading, topical organization, summarizing. 


\section{Introdução}

Este trabalho pretende ser uma aplicação de uma perspectiva teórico-analítica sobre o funcionamento do texto ao ensino, especificamente ao ensino de leitura, concebida como processo ativo e criativo de compreensão e produção de sentido. A perspectiva teórico-analítica em questão é a que concebe a topicalidade como um princípio organizador do texto. A análise da organização tópica do texto leva em consideração a identificação e delimitação de segmentos tópicos e dos procedimentos pelos quais esses segmentos se distribuem na linearidade do texto (organização linear) e se recobrem hierarquicamente conforme o grau de abrangência dos assuntos (organização hierárquica).

Defende-se que exercício de análise da organização tópica possibilita o desenvolvimento da habilidade de sumarização das informações, já que envolve, necessariamente, o processo de abstração dessas informações em macroproposições semânticas. Propõe-se, assim, que a atividade de sumarização/resumo do texto pelo viés da sua organização tópica se reverte em uma estratégia de ensino de leitura.

A discussão está textualizada em quatro partes: na primeira, retomam-se alguns trabalhos sobre a atividade de sumarização e demonstra-se que ela serve de indicador do nível de eficiência de leitura, e que pode, também, ser tomada como estratégia de ensino de leitura; na segunda parte, discute-se a topicalidade como princípio de organização textual e seus desdobramentos; na terceira, expõe-se, sumariamente, a perspectiva de leitura que embasa a discussão; e finalmente, aponta-se como o exercício de análise da organização tópica do texto se relaciona com o exercício de sumarização, tendo em vista a compreensão leitora.

\section{A atividade de sumarização}

Segundo Van Dijk (1978), o resumo é uma manifestação do processo de compreensão textual do leitor-resumidor, uma vez que, para o autor, o processo de leitura é baseado na redução do texto-fonte através de suas proposições, ou microestrutura, até chegar a sua estrutura global ou significação básica, ou macroestrutura. Essa redução se dá através da aplicação de macrorregras, interiorizadas pelo leitor ao longo dos anos. Tais regras seriam de dois tipos básicos: apagamento e substituição. As regras de apagamento são seletivas, pois selecionam o que é relevante para o texto, suprimindo o irrelevante. Ao contrário, as regras de substituição não suprimem informações, mas exigem que o leitor construa novas proposições, integrando as informações expressas no texto-fonte ou seus pressupostos. Nesse sentido, elas podem ser consideradas como regras construtivas.

A aplicação dessas regras está condicionada não somente ao conjunto de conhecimentos lingüísticos, textuais, crenças e valores que o leitor traz para o texto, mas também ao objetivo da leitura, intenção do autor, tipo de contexto social em que se dá a leitura, dando origem a textos bastante variáveis, caracterizados não como reproduções do texto-fonte, mas como novos textos.

Sousa e Silva (1985) examina o resumo sob um ponto de vista diferente, o do produtor-resumidor. A caracterização do resumo, não simplesmente como uma réplica do discurso original, mas como um novo texto, que satisfaz as condições de uma nova situação de comunicação, como coloca Van Dijk (1978), envolve, segundo a autora, em 
sua elaboração, a solução de problemas semelhantes aos encontrados numa tarefa de produção.

Nesse sentido, segue a opinião de Perelman de Solarz (1994), que aborda a construção do resumo numa concepção psicogenética da aprendizagem, assumindo a postura interativa entre leitura e escrita. Segundo a autora, o resumo é uma re-escrita que envolve, logicamente, a leitura do texto-fonte. Isso significa que o sujeito produz seu texto a partir da construção do significado de outro texto. Nesse processo interativo, intervêm tanto as propriedades do texto-fonte como as possibilidades conceituais do sujeito.

Na esteira desses trabalhos, Pinheiro (2001) realiza um estudo sobre a produção de resumos de textos acadêmicos por estudantes universitários. O autor conclui que, para resumir, os estudantes universitários condensam ou reformulam o significado do texto-fonte, alguns em nível global, outros em nível local. No entanto, essas estratégias de redução semântica não garantem a construção de um resumo coerente, o que leva a crer que ou as macrorregras de sumarização não promovem a compreensão ou a dificuldade dos alunos não está na identificação da macroestrutura do texto-fonte, mas na reestruturação, já que esse processo exige um maior grau de abstração.

Essa conclusão converge para a de Sousa e Silva (1985), segundo a qual o tipo de regra de redução semântica utilizado e a eficiência no domínio dessas regras são determinados, principalmente, pela capacidade do redator em tomar decisões adequadas em cada um dos processos de escrita. Para Sousa e Silva (1985), as decisões envolvidas na atividade de redução da informação perpassam o processo de escrita como um todo, implicando um conjunto mais amplo de escolhas em nível de planejamento, tradução e revisão, que vão além do tipo de tarefa (resumo com o texto-fonte presente) e da escolaridade do aluno. O sujeito não domina as regras do funcionamento textual, as quais exigem abstração de informação para a construção de macroproposições semânticas, porque também não domina todas as exigências das etapas de produção do texto.

Esses e alguns outros estudos sobre a atividade de sumarização, embora divergentes em alguns pressupostos e conclusões, apontam para uma questão comum: sumarizar ou resumir um texto necessariamente envolve a habilidade de leitura eficiente, ou seja, leitura com compreensão. Um leitor só será capaz de resumir, de forma eficiente, um texto, se, entre outras habilidades, for capaz de abstrair informações em macroproposições semânticas. Dessa forma, a prática de sumarização, além de ser tomada como um indicador do nível de eficiência de leitura, pode, também, funcionar como estratégia de ensino de leitura.

\section{O processo da leitura}

Teoricamente existem três modelos básicos que explicam o processo cognitivo da leitura, que têm contribuído de forma significativa para o ensino: o modelo ascendente (bottom-up) defendido por Gough (1972, 1985), que privilegia as partes (palavras e expressões do texto); o modelo descendente (top-down), defendido por Goodman (1985, 1988), segundo a leitura é processada globalmente, por hipotetização, considerando o conhecimento prévio do leitor; e o modelo interativo defendido por Rumelhart $(1977,1985)$, que procura unir os dois subprocessos bottom-up e top-down, simultaneamente ou alternadamente. 
A teoria bottom-up argumenta que o leitor constrói o texto a partir das pequenas unidades (letras para palavras para frases para sentenças, etc.). Decodificação é o termo mais apropriado para esse processo. A teoria top-down argumenta que os leitores trazem seu próprio conhecimento, suas experiências e suas dúvidas para o texto e vão formulando hipóteses. Continuam lendo o texto até que as hipóteses sejam confirmadas. A teoria interativa argumenta que os processos top-down e bottom-up ocorrem alternados ou ao mesmo tempo.

Considerando esses modelos, há também três tipos de leitor. O primeiro tipo é aquele que enfatiza o processo ascendente. Constrói o significado principalmente com base nos dados do texto, fazendo pouca leitura ou quase nenhuma das suas entrelinhas do texto, detendo-se vagarosamente nas palavras. Esse procedimento valoriza o vocabulário do texto, dando atenção às partes menores do texto. O segundo tipo de leitor privilegia a abordagem descendente. Ele apreende rapidamente as idéias gerais e essenciais do texto. Conseqüentemente, este tipo de leitor é o que faz mais uso de seu conhecimento prévio do que da informação propriamente dita do texto. Nesse processo descendente, o leitor estimula os chamados pacotes de esquemas, isto é, conhecimentos já estruturados, acompanhados de instruções para determinado uso. Esses pacotes de esquemas ligam-se a outros esquemas ou subesquemas e acionam uma rede de interrelações que são ativadas no ato da leitura, produzindo significações e situações novas. O terceiro tipo de leitor é aquele que processa os dois modelos paralelamente, conforme as exigências do texto e da situação de leitura. Pode-se registrar que se trata de um leitor maduro e competente, com alto grau de proficiência em leitura.

Recolocando o que dizem esses modelos, caracteriza-se, então, a leitura como um processo analítico, construtivo e estratégico. Analítico porque a compreensão se dá do todo para as partes, das unidades maiores para as menores; construtivo, porque o leitor exerce um papel ativo antes, durante e após a leitura na construção do significado; estratégico, porque o leitor faz uso consciente das habilidades de leitura adquiridas. Além dessa natureza analítica, construtiva e estratégica, o processo da leitura é também interativo, isto é, exige o envolvimento do leitor com as informações do texto.

Esse processo envolve o uso de estratégias de predição, confirmação e integração. Através delas o leitor forma expectativas sobre o que vai ler, busca respostas do texto e seleciona para reter na memória o que parece relevante. Essas estratégias podem ser inconscientes (cognitivas) ou conscientes (metacognitivas). As cognitivas consistem na atualização das regras da gramática interna do sujeito, ou seja, da utilização inconsciente dos elementos formais do texto para construir significado. Essas estratégias podem ser monitoradas pelas estratégias metacognitivas. Na leitura, essas estratégias metacognitivas podem atuar a priori (quando o leitor seleciona o que vai fazer), ou a posteriori (quando se defronta com o insucesso). São essas estratégias que devem ser alvo de atenção nas atividades instrucionais de leitura: o conhecimento do leitor de seus recursos cognitivos, ou seja, daquilo que ele sabe, e o uso de mecanismos auto-reguladores, tais como planejar, monitorar a eficácia, avaliar o resultado do que fez ou do uso de uma estratégia.

\section{A organização tópica do texto}

O tópico, segundo Brown e Yule (1983, p. 73), pode ser entendido como "o assunto acerca do qual se está falando ou escrevendo”, e está na dependência de um processo colaborativo que envolve os participantes do ato comunicativo. 
Nessa mesma linha se posiciona o trabalho de Jubran et al. (1992). Conforme os autores, o tópico é uma categoria abstrata, primitiva, que se manifesta "na conversação, mediante enunciados formulados pelos interlocutores a respeito de um conjunto de referentes explícitos ou inferíveis, concernentes entre si e em relevância num determinado ponto da mensagem” (JUBRAN, 1992, p. 361). O tópico, nessa perspectiva, abrange duas propriedades que o particularizam: a centração e a organicidade. A centração abrange os seguintes traços:

a) concernência: relação de interdependência semântica entre os enunciados implicativa, associativa, exemplificativa ou de outra ordem - pela qual se dá sua integração no referido conjunto de referentes explícitos ou inferíveis; b) relevância: proeminência desse conjunto, decorrente da posição focal assumida pelos seus elementos; c) pontualização: localização desse conjunto, tido como focal, em determinado momento da mensagem. (JUBRAN et al., 1992, p. 360)

Considerando que, em um único evento de fala/escrita, os interlocutores podem desenvolver vários temas, e, portanto, vários tópicos, é possível abstrair-se desse evento uma dada organicidade, expressa na distribuição dos assuntos em quadros tópicos. Para Jubran et al. (1992), a organização tópica pode ser observada em dois níveis: no plano hierárquico e no plano seqüencial. No plano hierárquico, as seqüências textuais se desdobram em supertópicos e subtópicos, dando origem a quadros tópicos, caracterizados, obrigatoriamente, pela centração num tópico mais abrangente e pela divisão interna em tópicos co-constituintes; e, possivelmente, por subdivisões sucessivas no interior de cada tópico co-constituinte, “de forma que um tópico pode vir a ser ao mesmo tempo supertópico ou subtópico, se mediar uma relação de dependência entre dois níveis não imediatos” (JUBRAN, 1992, p. 364).

Sobre o plano seqüencial, dois processos básicos caracterizam a distribuição de tópicos na linearidade discursiva: a continuidade e a descontinuidade. A continuidade se caracteriza por uma relação de adjacência entre dois tópicos, com abertura de um tópico subseqüente somente quando o anterior é esgotado. A descontinuidade se caracteriza por uma perturbação da seqüencialidade linear, causada ou por uma suspensão definitiva de um tópico, ou pela cisão do tópico, que passa a se apresentar em partes descontínuas.

Em trabalho sobre a organização tópica de diferentes gêneros de texto, falados e escritos, Pinheiro (2006) constata que em todos os textos analisados, a noção de topicalidade se evidencia. É possível depreender uma organização dos assuntos tratados, no plano vertical. No entanto, à medida que os textos medialmente escritos se aproximam, conceptualmente, da fala, ou vice-versa, vão sofrendo um processo de descontinuidade na organização linear dos segmentos tópicos.

Em textos como carta pessoal e conversação espontânea, os segmentos de um mesmo tópico nem sempre são adjacentes. Eles são constantemente entremeados por outros segmentos, sejam esses inserções de outros tópicos ou inserções parentéticas. Entretanto, a organização seqüencial, perturbada na linearidade, se restabelece num nível mais alto e abstrato, o da hierarquia tópica, sem prejudicar o estabelecimento da coerência. Todos os tópicos apresentam início, meio e fim, embora sejam desenvolvidos em diferentes momentos do texto.

Outros textos, mais prototipicamente escritos, como artigo de opinião e artigo científico, por exemplo, no que diz respeito à organização seqüencial dos segmentos tópicos, se caracterizam pela constante linearidade. Cada tópico, em geral, encerra um 
argumento a serviço da idéia central defendida pelo autor. E cada tópico só se inicia quando o anterior é concluído.

Fundamenta-se, neste artigo, que a topicalidade, como um princípio de organização textual, pode ser tomada como um pressuposto para o desenvolvimento de estratégias metacognitivas nas atividades instrucionais (cf. sessão anterior) de ensino de leitura. Uma dessas estratégias envolve a sumarização das informações a partir do processo de segmentação tópica do texto.

\section{A segmentação tópica do texto e a compreensão leitora}

Operando com a categoria de tópico discursivo, Jubran et al. (1992, p. 363) chegam à identificação e delimitação de segmentos tópicos, "isto é, unidades discursivas que atualizam as propriedades do tópico”. Dessa forma, enquanto o tópico discursivo é uma categoria analítica abstrata, o segmento tópico é a seqüência textual que preenche as propriedades dessa categoria.

O segmento tópico é, portanto, a unidade que, em termos de centração, revela concernência e relevância no conjunto de seus elementos e se localiza num determinado ponto do evento comunicativo (pontualização), submetida à organização tópica negociada pelos falantes. O segmento tópico, em outras palavras, constitui cada conjunto de enunciados tematicamente centrados.

Como unidade de composição textual, o segmento tópico reúne as mesmas características formulativo-interacionais do texto, ou seja, se constitui como uma unidade estrategicamente organizada veiculadora de sentido. Através da observação do segmento tópico é possível isolar convenientemente as informações do texto e acompanhar os seus diferentes estágios de desenvolvimento, o que permite verificar processos globais de organização textual.

É nesse sentido que se propõe a atividade de segmentação tópica do texto como uma eficiente estratégia de ensino da leitura de textos. O procedimento de identificar as seqüências discursivas que configuram um tópico discursivo envolve a habilidade de reunir em macroproposições semânticas um conjunto pontual de informações, que já constitui também um processo de sumarização. Por sua vez, o procedimento de identificar a organização hierárquica dessas seqüências discursivas possibilita 0 entendimento da estrutura do texto e a forma como as informações estão interrelacionadas, o que, no final, possibilita a construção do sentido global do texto.

Com base na categoria analítica de tópico discursivo, o texto $(01)^{1}$ pode ser recortado em seis segmentos, tal como está transcrito a seguir. Cada um desses segmentos corresponde aos tópicos que estão no último nível da hierarquia, dentro de cada quadro tópico, ou seja, aos quais nenhum outro tópico se subordina, conforme pode ser visualizado no diagrama correspondente.

O texto está dividido em seis segmentos, organizados em torno de um tópico principal, correspondente a um primeiro nível da organização tópica hierárquica: (A) $A$ pós-graduação no Brasil. Esse tópico se subdivide em níveis sucessivos de detalhamento, de modo que os seus subtópicos se desdobram em outros. Assim, apresenta, no segundo nível hierárquico do texto, três tópicos: (A1) A idéia de douta ignorância, (A2) Funcionamento da pós-graduação no Brasil e (A3) Avaliação geral

\footnotetext{
${ }^{1}$ Artigo de opinião E-257 do corpus do NELFE (Núcleo de Estudos da Língua Falada e Escrita) - programa de PósGraduação em Lingüística da UFPE (Universidade Federal de Pernambuco - Brasil).
} 
sobre a pós-graduação. Dentro de (A2) há um terceiro plano, com os subtópicos (A2.1) Parecer de Newton Sucupira, (A2.2) Princípios da pós-graduação e (A2.3) Efetividade da pós-graduação. E há, ainda, um quarto plano, já que um desses dois subtópicos, por sua vez, se subdivide em outros dois: (A2.2) comporta o (a2.1) Objetivo e o (a2.2) Exigências.

Em termos de linearidade discursiva, o tópico (A1) recobre o segmento 1, o (A2) abarca os segmentos de 2 a 5, assim distribuídos: o 2 configura o tópico (A2.1), 3 e 4 integram respectivamente as subdivisões de (A2.2) em (a2.1) e (a2.2), e 5 recobre o subtópico A2.3. O segmento 6 configura o tópico A3.

É preciso ressaltar, no entanto, que a noção de segmento, do ponto de vista prático de análise, é relacional, porque está associada aos diferentes níveis dessa organização hierárquica. Dessa forma, dependendo do nível que o analista colocar sob enfoque, diferentes formas de segmentação são possíveis. Se a segmentação for depreendida somente a partir dos quadros tópicos de segundo nível (A idéia de "Douta ignorância", Funcionamento da pós-graduação no Brasil e Avaliação geral sobre a pós-graduação), por exemplo, o texto apresentará apenas três segmentos: o primeiro, que corresponde ao segmento 1 , o segundo, que corresponde a toda a extensão textual que vai do segmento 2 ao 5, e o terceiro, que corresponde ao segmento 6. Não será levada em conta, portanto, a subsegmentação do segundo tópico.

\section{Texto 01}

[1 No prólogo do segundo volume de seus Diálogos, São Gregório Magno escreve que ao desprezar os estudos literários iniciados em Roma, adotando a vida monástica, nosso pai São Bento preferia ser "doutamente ignorante e sabiamente insensato" (scienter nescius et sapienter indoctus). Reportava-se, evidentemente, à douta ignorância de que fala Santo Agostinho em carta à Proba. Mais tarde, Nicolau de Cusa definiu a expressão em seu livro de 1440 De docta ignorantia: "Nada podemos saber de Deus que, por ser infinito, está além de toda proporção com o finito, isto é, o homem”. Mas douta ignorância também se define, de modo genérico, como "a consciência dos limites do próprio saber”, como ensina Nicola Abbagnamo em seu excelente Dicionário de filosofia.]

[2 Lembrei-me disso ao ler a reportagem da revista Veja sobre as misérias da pós-graduação no Brasil. Quando o professor Newton Sucupira escreveu seu histórico e lúcido parecer a respeito do assunto, advertiu as universidades para o perigo que podia transformar a pós-graduação num fracasso: o de contaminar-se com a impostura do chamado ensino superior entre nós.

Como a voz do Batista, a de meu amigo Sucupira foi vox clamantis in deserto, porque as universidades não fizeram outra coisa senão abastardarem os graus de mestre e doutor. Temos, aliás, no Brasil, a triste tradição de desmoralizar palavras que, no estrangeiro, são quase sagradas. Já me referi, neste jornal, ao que acontece com filósofo, historiador, antropólogo e sociólogo, títulos com os quais são brindados entre nós, simples professores de filosofia, história, antropologia e filosofia.]

[3 Para que serve a pós-graduação? Para fazer com que as universidades sejam não apenas transmissoras, mas produtoras de cultura, contribuindo para o desenvolvimento da filosofia, da ciência, das letras e das artes.] [4 Exige-se do candidato ao grau de mestre que demonstre em sua dissertação o domínio de métodos, conhecimento da matéria e capacidade de sistematização. Mas a quem 
pretende o grau de doutor a exigência é que sua tese contenha uma contribuição original à área do conhecimento que se insere determinado tema.]

[5 Vê-se pela reportagem aqui comentada que nas universidade brasileiras, com raras exceções, não acontece nada disso. Que as teses são verdadeiros bestialógicos, como a de um professor de filosofia do Recife, aprovada porque os examinadores queriam se ver livres dele (sic!).

Sabe-se também que depois de obterem o grau, os doutores não fazem mais pesquisas nem publicam. Mas ganham gratificações que tornam seus salários muito mais altos do que os dos simples bacharéis. Estes, coitados, continuam pesquisando, publicando e até integrando bancas examinadoras de teses de doutoramento.]

[6 As universidades valorizam mais os doutos indoutos do que os não doutores que pesquisam mesmo depois de aposentados por limite de idade, que integraram colegiados de pesquisa e pós-graduação e foram assessores de instituições nacionais e estrangeiras. Valorização do formal em detrimento do essencial. Desserviço ao desenvolvimento científico e humanístico. Traição aos objetivos da pós-graduação.]

Diagrama de organização tópica hierárquica do texto 01

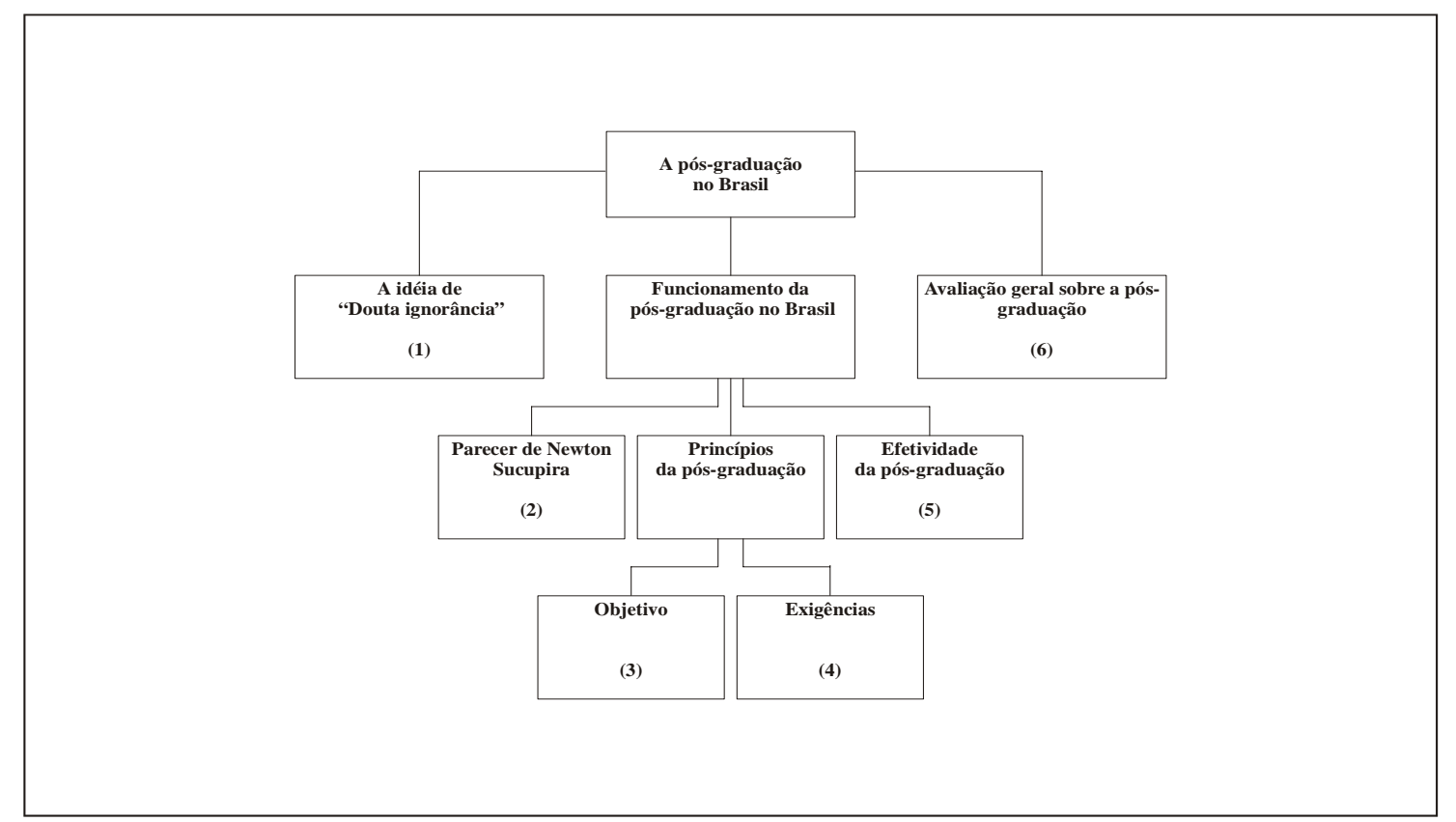

Considerando essa análise da organização tópica do texto como pressuposto para o ensino de leitura, uma das atividades possíveis de serem realizadas com o texto, em sala de aula, é, exatamente, a identificação do tópico, da sua particularização hierarquizada, e conseqüente distribuição seqüencial na linha discursiva. Cada uma dessas atividades envolve o processo de sumarização. Ao processo de atribuir rótulos aos tópicos recobertos por cada segmento, por exemplo, subjaz a habilidade de perceber e condensar os elementos textuais em centração. No segmento 1, a repetição da expressão douta ignorância instaura a centração tópica. A mudança de centração no segmento 2 é bastante visível, marcada pela expressão pós-graduação no Brasil. Também aí se configura o exercício de perceber a instauração de um tópico mais amplo 
(o funcionamento da pós-graduação no Brasil), e seus desdobramentos através de expressões textuais que vão instaurando novas centrações: parecer, que instaura o subtópico parecer Newton Sucupira, no segmento 2; para fazer, que instaura o subtópico objetivos, no segmento 3; e exige-se/a exigência, que instauram o subtópico exigências, no segmento 4.

No procedimento de observar as dependências dos tópicos no plano vertical, através das relações de super e subordenação entre eles, subjaz também a habilidade de sumarização, só que no nível das relações de sentido entre as várias informações do texto e a forma como elas estão organizadas, tendo em vista o sentido global pretendido pelo autor. No texto, o tópico Douta ignorância, por exemplo, é tomado como ponto de partida para desencadear informações sobre o Funcionamento da pós-graduação no Brasil, tendo em vista uma avaliação geral dessa pós-graduação.

Segundo o modelo interativo de leitura, sumariamente apresentado na sessão 2, o conhecimento prévio das formas de organização típicas que definem um tipo de texto, ou seja, os modelos de organização textual, propiciam ao leitor antecipar informações que seriam apresentadas dentro de um modele de organização. Essa antecipação constitui um dos elementos que permite que o processo de compreensão seja ativado, formando uma base para as expectativas geradas pelo leitor (antes ou durante a leitura). Essas seriam confirmadas através de características textuais que corresponderiam ao princípio geral de organização de um texto especifico. No momento em que o leitor se familiariza com modelos de organização textual, ele passa a ter uma representação mental que propicia o desenvolvimento de esquemas textuais.

As atividades de sumarização do texto pelo viés da sua organização tópica aqui descritas constituem uma estratégia de desenvolvimento de uma planificação consciente, antes e durante a leitura. Essa estratégia leva o leitor a construir um quadro de sentidos, pois, entre outras coisas, pode categorizar as idéias que estabelecem a estrutura do texto (principais e secundárias) e configurar a relação entre essas idéias. Ele vai, assim, se familiarizando com vários de tipos de estruturas organizacionais dos diferentes gêneros de texto.

\section{Conclusão}

Neste trabalho, foi apresentada uma discussão que indica a possibilidade de a topicalidade representar um pressuposto a ser tomado no ensino de leitura. $\mathrm{O}$ procedimento de identificar as seqüências discursivas que configuram um tópico discursivo e a sua organização hierárquica podem possibilitar o entendimento da estrutura do texto e a assimilação das informações. É então proposta a análise da organização tópica dos textos como uma estratégia de ensino para o desenvolvimento da habilidade de sumarizar o texto, e, de se chegar à construção do seu sentido.

\section{Referências}

BROWN, Gillian; YULE, George. Discourse analysis. Cambridge: Cambridge University Press, 1983. 
GOODMAN, Kenneth. Unity in reading. In: SINGER H.; RUDDELL, R. B. Theoretical model and processes of reading. Newark, Delaware: International Reading Association, 1985.

The reading process. In: CARRELL, P. L.; DEVINE, J.; ESKEY, D. E. (Eds.). Interactive approaches to second language reading. Cambridge: Cambridge University Press, 1988.

GOUGH, Philip B. One second of reading. In: KAVANAGH, J. F.; MATTINGLY, I. G. (Orgs.). Language by ear and by eye. Cambridge: MIT Press, 1972.

One second of reading. In: SINGER H.; RUDDELL, R. B. Theoretical model and processes of reading. Newark, Delaware: International Reading Association, 1985.

JUBRAN, Clélia C. A. S. et al. Organização tópica da conversação. In: ILARI, R. (Org.). Gramática do português falado, v. II. Campinas/SP: UNICAMP, São Paulo: FAPESP, 1992.

PERELMAN DE SOLARZ, Flora. La Construccion del resumen. Lectura y Vida, ano 15, n. 3, p. 28-46, Buenos Aires, IRA, 1994.

PINHEIRO, Clemilton Lopes. A prática do resumo no contexto universitário. Athos \& Ethos, v. 1, Patrocício-MG, Faculdade do Patrocínio, p. 117-140, 2001.

Organização tópica na fala e na escrita. In: SOARES, M. E. (Org.). Pesquisas em lingüística: descrição, aplicação, ensino. Fortaleza: PPGL-UFC/GELNE, 2006.

RUMELHART, David E. Toward an interactive model of reading. In: DORNIC, S. Attention and performance VI. Hillsdale, NJ: Erlbaum, 1977.

Toward an interactive model of reading. In: SINGER, H; RUDDELL, R. Theoretical models and process of reading. 3rd ed. Newark, Delaware: International Reading Association, 1985.

SOUSA E SILVA, Maria Cecília P. A tarefa de sumarização num contexto mais amplo de produção escrita. In: I CONGRESSO BRASILEIRO DE LINGÜÍSTICA APLICADA. Anais, Campinas, UNICAMP, 1985.

VAN DIJK, Teun A. La ciencia del texto. Barcelona: Paidós, 1978. 